\title{
Population Dynamics of Free-Roaming Cats in Florida's Lee County
}

Benjamin Taylor
University of South Florida

\author{
Advisors: \\ Arcadii Grinshpan, Mathematics and Statistics \\ Christopher Taylor, Lee County Animal Services \\ Problem Suggested By: Christopher Taylor
}

Follow this and additional works at: https://digitalcommons.usf.edu/ujmm

Part of the Mathematics Commons

UJMM is an open access journal, free to authors and readers, and relies on your support:

Donate Now

\section{Recommended Citation}

Taylor, Benjamin (2010) "Population Dynamics of Free-Roaming Cats in Florida's Lee County," Undergraduate Journal of Mathematical Modeling: One + Two: Vol. 3: Iss. 1, Article 4.

DOI: http://dx.doi.org/10.5038/2326-3652.3.1.16

Available at: https://digitalcommons.usf.edu/ujmm/vol3/iss1/16 


\title{
Population Dynamics of Free-Roaming Cats in Florida's Lee County
}

\begin{abstract}
We investigate whether the Trap-Neuter-Return (TNR) program can be effectively used to control the population of free-roaming cats in Florida's Lee County. We do this by estimating the number of cats that must be spayed/neutered in order to keep the population from increasing.
\end{abstract}

Keywords

Free-roaming Cats, Trap Neuter-Return, Population Dynamics

Creative Commons License

(c) (i) ()

This work is licensed under a Creative Commons Attribution-Noncommercial-Share Alike 4.0 License.

\section{Erratum}

This article was previously called Article 16. 


\section{TABLE OF CONTENTS}

Problem Statement

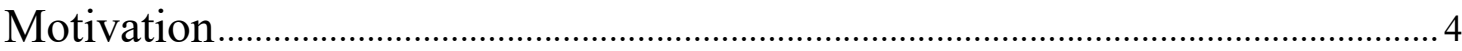

Mathematical Description and Solution Approach ................................................ 4

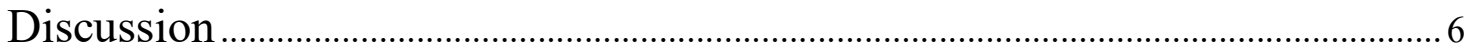

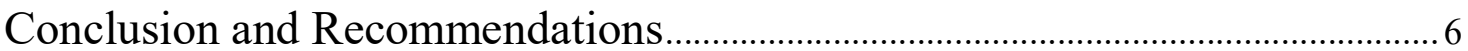

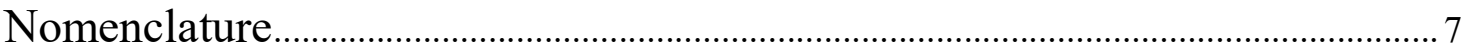

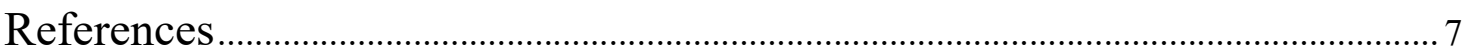

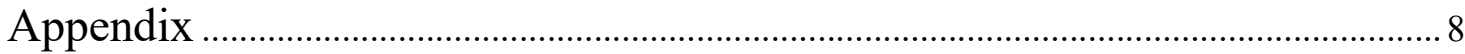




\section{PROBLEM STATEMENT}

Controlling the population of free-roaming cats is a long-standing challenge for many cities and counties. Studies suggest that large numbers of these felines infected with rabies, plague, or toxoplasmosis can present a risk to public health (Kirkwood, Patronek). Welfare of these cats is also a major concern to many individuals, humane societies, and shelters (see http://feralcatproject.org/). There are a number of measures employed by these organizations to control the cat population. One of them is euthanasia and the other is called Trap-Neuter-Return or TNR. During TNR the cats are spayed/neutered, vaccinated and later released back to their capture site. Many agree that TNR is a more humane way to deal with cat overpopulation than euthanasia. The cats that underwent TNR live the rest of their natural lives in their original habitat while causing fewer nuisances typically associated with feral cats (TNR Program).

In this project, we attempt to estimate the weekly number of cats that must be spayed/neutered in order to prevent the population from increasing.

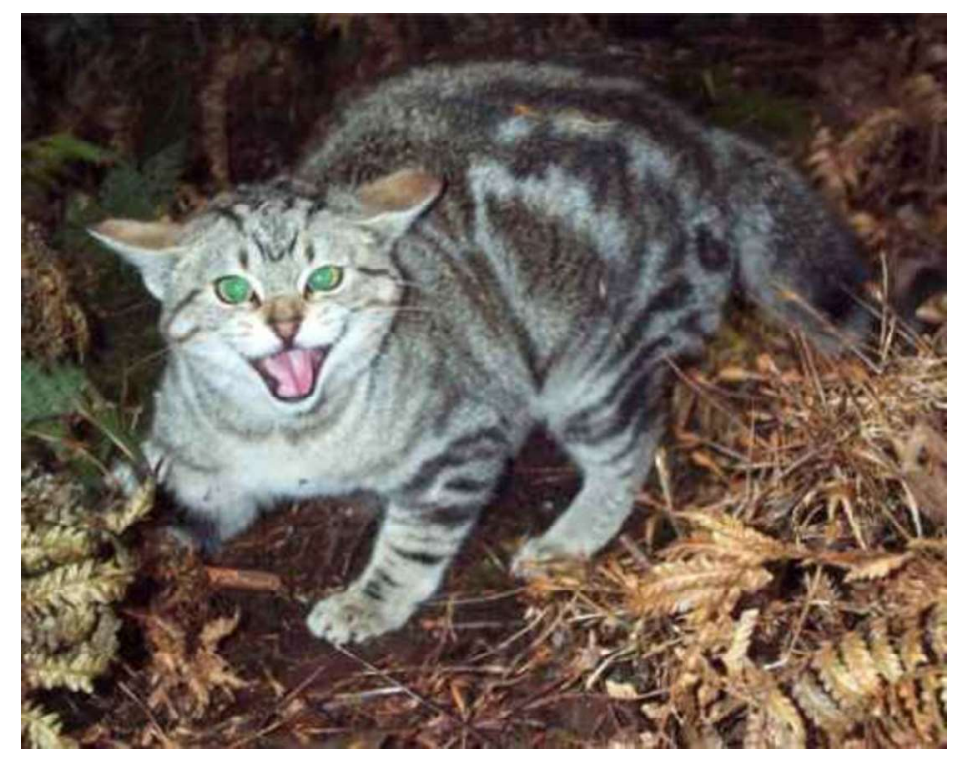

Figure 1: Free-Roaming Tabby Cat 


\section{MOTIVATION}

Nutter et al. estimated that free-roaming cats produce 1.4 litters per year with a median of 3 kittens per litter, and that $75 \%$ of kittens die or disappear before reaching maturity (Nutter et al.). We use these statistics to investigate the dynamics of feral cat population in Lee County, Florida that housed a population of 98,000 feral cats in 1998 according to some estimates (Lee County National Feral Cat Day Announcement). Although the average lifespan of a free-roaming or a feral cat is difficult to estimate, we assume it to be 3 years (see (Warner) for more precise estimates).

Nutter et al. also confirmed the popular opinion that most cat's pregnancies occur during spring (Nutter et al.). Since kittens reach reproductive age within a year, they can contribute to the population growth in the subsequent spring. Because of this, we use the discrete version of density-independent population growth model to investigate cat population dynamics (see (Loreau) for a detailed description of this model).

\section{MATHEMATICAL DESCRIPTION AND SOLUTION APPROACH}

According to discrete density-independent population growth model, $N(t)$, the freeroaming cat population at time $t$, is governed by the following recurrence relation:

$$
N(t+1)=N(t)+B(t)-D(t)+I(t)-E(t)
$$

where $B$ is the number of births, $D$ is the number of deaths, $I$ is the number individuals migrated into the area under study, and $E$ are the number of individuals that migrated away. Each value is given per a priori selected time period (one year for our study). We do not include the number of 
spayed/neutered cats in the population $N(t)$ because these cats do not participate in reproduction. Furthermore, if $n$ cats are spayed/neutered each year, then there are approximately $3 n$ of the total population will be sterile at any given time.

For our analysis we use an additional quantity $L$ that stands for the total number of new litters per given year. That is,

$$
L(t)=1.4\left(\frac{N(t)}{2}\right)
$$

assuming each female cat on average produces 1.4 litters per year and that half of the cat population are female. Then

$$
B(t)=\frac{3 L(t)}{4}=0.575 N(t)
$$

because the median number of kittens per litter is 3 and $75 \%$ of kittens die before reaching maturity.

Assuming that the age of cats in the population is evenly distributed each year, we get that a third of all cats die during a given year, or

$$
D(t)=0.333 N(t)
$$

For simplicity we consider the population to be closed, i.e. both $I$ and $E$ are zero.

However replacing $E$ with the number of cats spayed/neutered, $n$, allows to exclude these cats from the population. In summary of (1)-(4), we get that

$$
\begin{aligned}
N(t+1) & =N(t)+0.575 N(t)-0.333 N(t)+0.000-n \\
& =1.192 N(t)-n
\end{aligned}
$$


For the equilibrium, we need $N(t+1)=N(t)$, which leads to $n=0.192 N(t)$ and, in the particular case of Lee county, $n=0.192 \cdot 98,000 \approx 19,600$ cats that need to be neutered each year. Since there are approximately 53 weeks in a year, we conclude that at least 370 cats have to be spayed/neutered each week to maintain the population equilibrium. Figure 1 in the Appendix shows a graph with the population sizes corresponding to the value of $n$ equal to the equilibrium, 200, and 100 spays/neuters per week.

\section{DISCUSSION}

Our analysis shows that keeping the population of free-roaming cats in Lee County from growing requires spaying/neutering of at least 370 cats per week. We suspect that this estimate is high because the model we considered is density independent. Nevertheless our results underline the rate at which the cat population can explode if not properly controlled.

\section{CONCLUSION AND RECOMMENDATIONS}

We have estimated that at least 370 cats must be spayed/neutered each week to prevent Lee County's cat population from growing. Our computations also suggest that the size of cat population can increase at an alarming rate if not properly controlled. Perhaps our results can be improved by considering more complicated models that account for slower growth of large populations of feral cats. 


\section{NOMENCLATURE}

\begin{tabular}{|cl|}
\hline $\begin{array}{c}\text { Symbol } \\
\boldsymbol{N}(\boldsymbol{t})\end{array}$ & \multicolumn{1}{c|}{ Description } \\
\hline $\boldsymbol{B}(\boldsymbol{t})$ & $\begin{array}{l}\text { Number of adult cats that were born during } \\
\text { year } t\end{array}$ \\
\hline $\boldsymbol{D}(\boldsymbol{t})$ & Number of adult cats died during year $t$ \\
\hline $\boldsymbol{L}(\boldsymbol{t})$ & Number of litters during year $t$ \\
\hline $\boldsymbol{n}$ & Number of cats spayed/neutered each year \\
\hline
\end{tabular}

\section{REFERENCES}

http://feralcatproject.org/. n.d. 13 November $2011<$ http://feralcatproject.org/>.

Kirkwood, Scott. "How Do Free-Roaming and Feral Cats Impact Humans and Wild Animals?" 1998. http://www.animalsheltering.org. 13 November 2011 $<$ http://www.animalsheltering.org/resource_library/magazine_articles/may_jun_1998/free_roami ng.pdf $>$.

"Lee County Hosts a Free Spay/Neuter and Vaccination Day for Community Feral Cats in Honor of National Feral Cat Day." n.d. Lee County Government Southwest Florida. 13 November 2011 $<$ http://www.leecounty.com/NewsReleases/Documents/Lee\%20County\%20Hosts\%20a\%20Free\%20Spay\%20Ne uter\%20and\%20Vaccination\%20Day.pdfs.

Loreau, Michel. From Populations to Ecosystems: Theoretical Foundations for a New Ecological Synthesis. Princeton University Press, 2010.

Nutter, F B, J F Levine and M K Stoskopf. "Reproductive capacity of free-roaming domestic cats and kitten survival rate." J Am Vet Med Assoc. (2004 ): 1399-402.

"Operation S.O.S. Community Cat Trap-Neuter-Return Program." n.d. Lee County Domestic Animal Services. 13 November $2011<$ http://leelostpets.org/Pages/Trap-Neuter-Return.aspx>.

Patronek, G J. "Free-roaming and feral cats--their impact on wildlife and human beings." J Am Vet Med Assoc (1998): 218-226.

Warner, R. E. "Demography and movements of freeranging domestic cats in rural Illinois Management." Journal of Wildlife (1985): 340-346. 


\section{APPENDIX - FIGURES}

\section{Cat Population Dynamics}

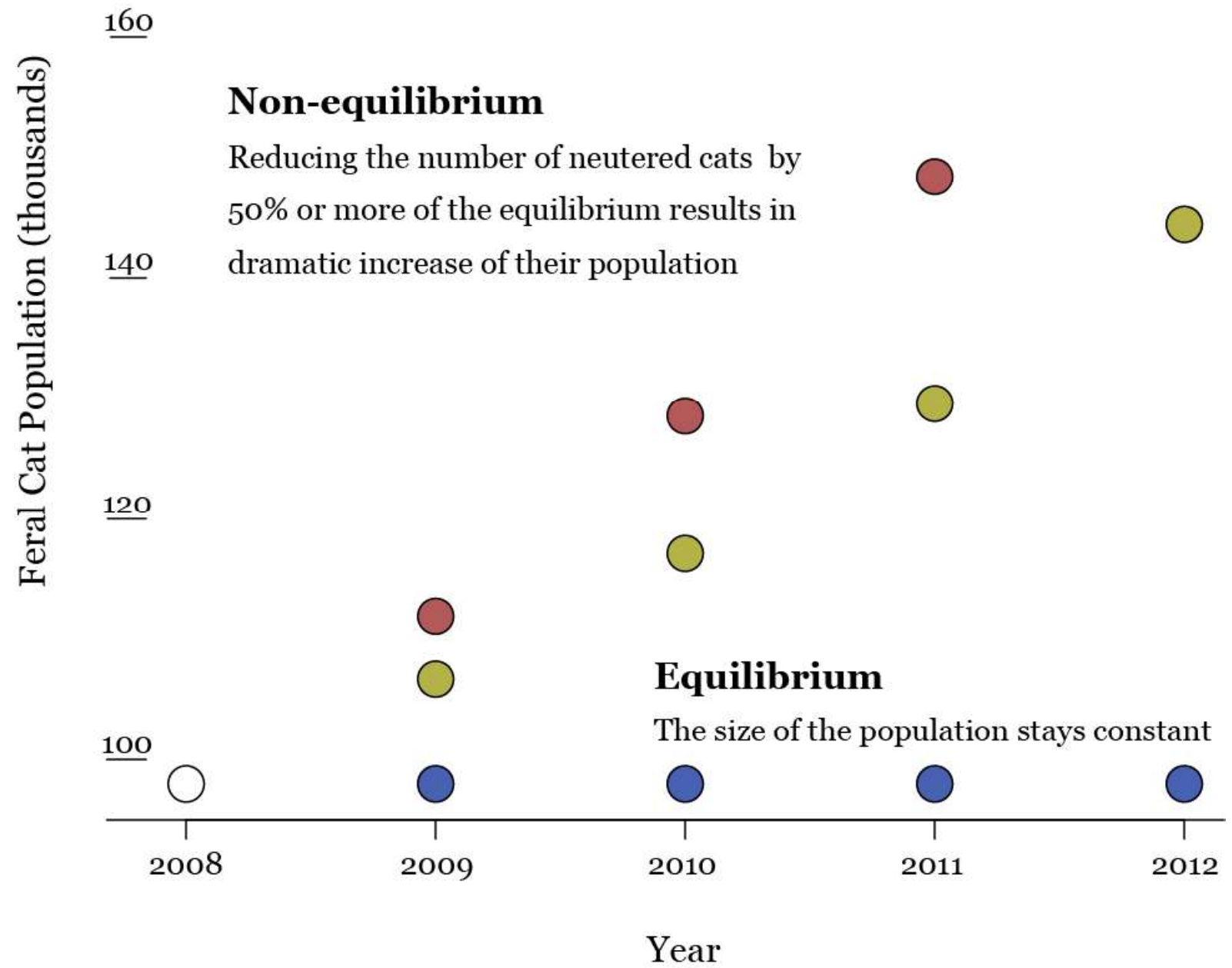

Figure 2: Projected populations of cats in Lee county, FL where 100 (red), 200 (tan) and 370 (blue) cats are spayed/neutered per week. 